() С. Є. Шейкін, д.т.н., професор, Інститут надтвердих матеріалів ім. В. М. Бакуля, Т. Ю. Киричок, д.т.н., професор, Т. Є. Клименко, к.т.н., ст.викладач, Н. Л. Талімонова, к.т.н., ст. викладач, КПІ ім. Ігоря Сікорського, Київ, Україна

\title{
КОРЕЛЯЦІЙНИЙ АНАЛІЗ ВЗАЕМОЗВ'ЯЗКУ МІЖ ХАРАКТЕРИСТИКАМИ ПОВЕРХНІ ЗАХИЩЕНОГО ПАПЕРУ ТА ОПТИЧНИМИ ХАРАКТЕРИСТИКАМИ ВІДБИТКІВ
}

\author{
Здійснено кореляційний аналіз взаємозв'язку \\ між характеристиками захищеного від підробки паперу \\ та оптичними характеристиками відбитків.
}

\section{Ключові слова: кореляційний аналіз; банкнотний папір; водяний знак; шорсткість паперу; оптична густина.}

\section{Постановка проблеми}

Насьогодні постійно зростають вимоги до забезпечення якості виготовлення банкнотної продукції на усіх етапах, у тому числі під час офсетного друку, який використовується для виготовлення банкнот усіх номіналів української гривні, зокрема вимоги до точності відтворення дрібних елементів зображення та колірності. Нині чинний ISO 12647-2 [1] регламентує вимоги до показників якості друкованої продукції офсетного способу друку. Якість банкнотного паперу є суттєвим фактором формування якості банкнотних відбитків в умовах багатосерійного виробництва [2, 3].

Статистичний аналіз якості захищеної продукції полягає в дослідженні умов і факторів, що впливають на якість аналізованого об'єкту. Аналіз виконаних експериментальних досліджень, у тому числі із застосуванням методу кореляції, дозволить ви- явити взаємозв'язок між характеристиками захищеного паперу та оптичними характеристиками відбитків [4]. Найбільш важливими факторами, що впливають на оптичні характеристики відбитків є однорідність поверхні, що задруковується та рівномірність розподілу фарбового шару на поверхні. Забезпечення якості друку досягається відповідністю вимогам якості таких показників: чіткість відтворення друкованого зображення та точність відтворення дрібних деталей, відхилення кольору в межах норми [5].

\section{Мета роботи}

Метою даної роботи є встановлення на основі кореляційного аналізу залежності між характеристиками захищеного паперу та оптичними характеристиками відбитків, в тому числі на ділянках водяного знаку.

(C) $2016 \mathrm{p}$. 


\section{Результати проведеного дослідження}

У роботі використано експериментальні дані попередніх досліджень, а саме фізико-технічні характеристики, параметри шорсткості та параметри фрактальної розмірності зразків банкнотного паперу [6], а також характеристики захищеного паперу з водяними знаками [7].

Взаємозв'язок між характеристиками поверхні паперу та якістю оптичних характеристик відбитків найкраще спостерігається при побудові графічних залежностей між відповідними показниками (рис. 1, 2). Встановлено залежність для кожного досліджуваного зразка банкнотного паперу. Розрахунок квадратичних відхилень експериментальних даних показав кореляцію між характеристиками поверхні паперу та параметрами оптичної густини $\left(\mathrm{D}_{\text {опт }}\right)$. Графічні залежності апроксимуються регресивними рівняннями з визначенням коефіцієнтів кореляції. Характеристики паперу порівнювали з досягнутими та нормованими показниками $\mathrm{D}_{\text {опт для чорної }}$ фарби при різній кількості фарби $\mathrm{h}_{\phi}$ на відбитку. Значення $\mathrm{D}_{\text {опт }}$ нормовані відповідно до ISO 126472 [1].

Після побудови графічних залежностей можна побачити, що при збільшенні непрозорості банкнотного паперу збільшується оптична густина відбитків, що пов'язано з пористою структурою, в яку всотується фарба, залишаючи тонкий шар на поверхні матеріалу (рис. 1, а). На рис. 1, б спостерігається зменшення оптичної густини при збільшенні показника пористості банк- нотного паперу. Використання паперу з меншою пористістю не призводить до збільшення оптичної густини відбитків, що пов'язано з поверхневою та дисперсно-пористою структурою, яка активно всотує шар фарби [8].

Згідно з результатами проведених досліджень, вбирна здатність суттєво впливає на оптичну густину $\mathrm{D}_{\text {опт. }}$ Спостерігається збільшення оптичної густини відбитків при збільшенні показника вбирної здатності паперу (рис. 1, в). Вбирна здатність (В) залежить від композиційного складу та структурних характеристик банкнотного паперу, що підтверджено експериментально [9].

Банкнотний папір з найменшими показниками шорсткості перебуває в допустимих межах оптичної густини відбитків, причому при збільшенні показника шорсткості $\mathrm{R}_{\mathrm{a}}$ оптична густина зменшується, а при збільшенні показників шорсткості $\mathrm{R}_{\mathrm{z}}$ та $\mathrm{R}_{\max }$ - збільшується, що пов'язано із забезпеченням повного друкарського контакту (рис. 2).

Слід також зазначити, що наведені результати підтверджені фрактальним аналізом. Фрактальну розмірність довільної фігури вимірюють за формулою:

$$
\mathrm{S}_{\mathrm{i}} \mathrm{h}_{\mathrm{i}}^{v_{\phi p}} \approx \mathrm{C},
$$

де с - деяка константа; $\mathrm{D}_{\phi p}-$ фрактальна розмірність фігури,

$$
\ln \left(S_{i}\right) \approx D_{\phi p} \ln \left(\frac{1}{n_{i}}\right)-\ln (c) .
$$

$$
\text { Функція } \mathrm{f}(\mathrm{x})=\mathrm{ax}+\mathrm{b} \text {, відхилен- }
$$

ня $є$ найменшим $\sum_{i=1}^{n}\left(f\left(x_{i}\right)-y_{i}\right)^{2}$, якщо 


$$
\begin{array}{r}
a=\frac{n \sum x_{i} y_{i} \sum x_{i} \sum y_{i}}{n \sum x_{i}^{2}\left(\sum x_{i}\right)^{2}}, \\
b=\frac{\sum x_{i}^{2} \sum y_{i} \sum x_{i} \sum x_{i} y_{i}}{n \sum x_{i}^{2}\left(\sum x_{i}\right)^{2}},
\end{array}
$$

$\mathrm{n} \sum \mathrm{x}_{\mathrm{i}}^{2}-\left(\sum \mathrm{x}_{\mathrm{i}}\right)^{2}=$$$
=\sum_{1 \leq<<j \leqslant n}\left(x_{i}-x_{j}\right)^{2}>0
$$

$$
\text { якщо } \mathrm{x}_{1}=\ldots=\mathrm{x}_{\mathrm{n}} \text {, }
$$

$$
x_{i}=\ln \left(\frac{1}{h_{i}}\right)=-\ln \left(h_{i}\right)
$$

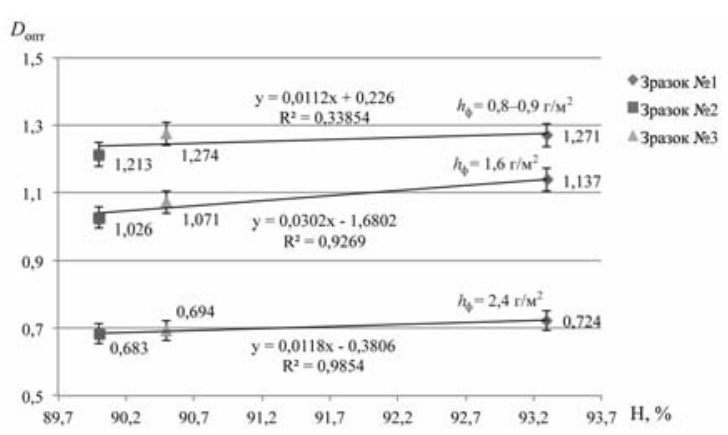

a
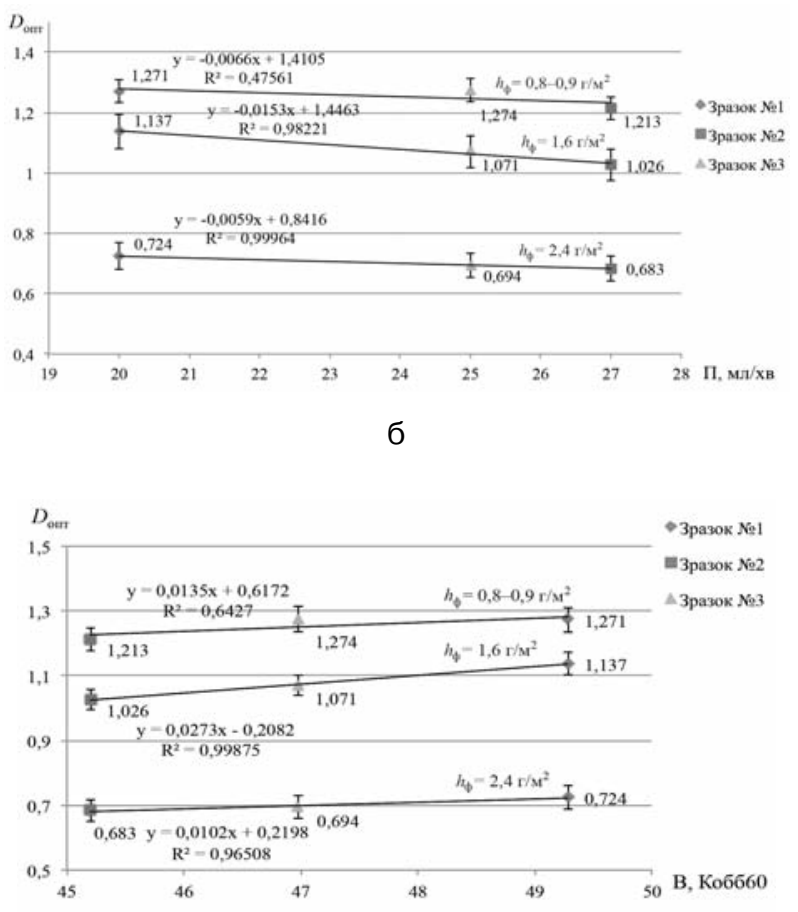

B

Рис. 1. Вплив непрозорості (Н), пористості (П) та вбирної здатності (В) паперу (a, б, в) на оптичну густину відбитків $\left(D_{\text {опт }}\right)$ 
$y_{i}=\ln \left(S_{i}\right),(i=1,2, \ldots, n)$.

$$
D_{\phi p}=\frac{n \sum x_{i} y_{i} \sum x_{i} \sum y_{i}}{n \sum x_{i}^{2}\left(\sum x_{i}\right)^{2}} .
$$

Функцію поверхні паперового аркуша розраховуємо за формулою:

$$
f(h) \approx \operatorname{Lch}^{\left(1 / D_{\phi p}\right)},
$$

де $\mathrm{L}$ - довжина паперового аркуша (L/h - кількість профілів); c - константа; $\mathrm{h}$ - крок зайнятих профілів; $\mathrm{D}_{\text {пр }}$ - фрактальна розмірність кожного профілю.
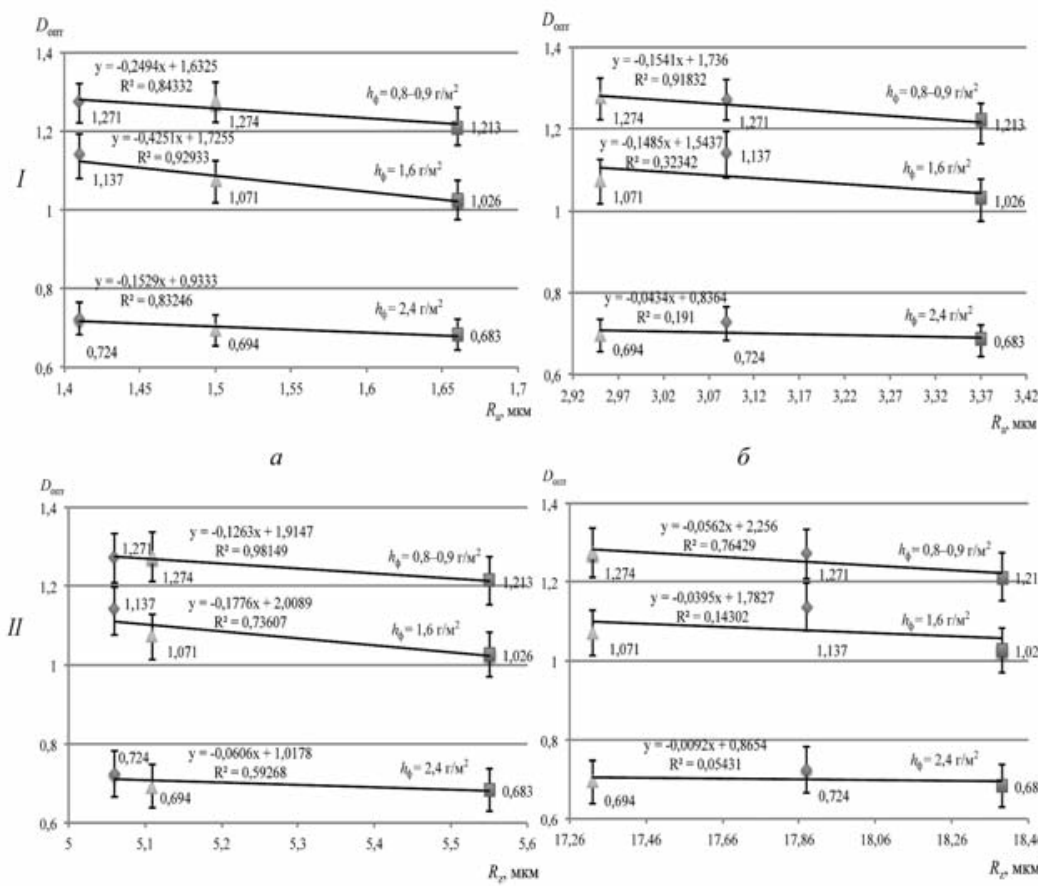

6

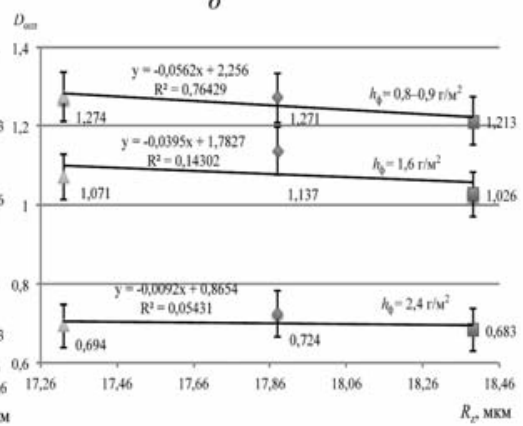

6

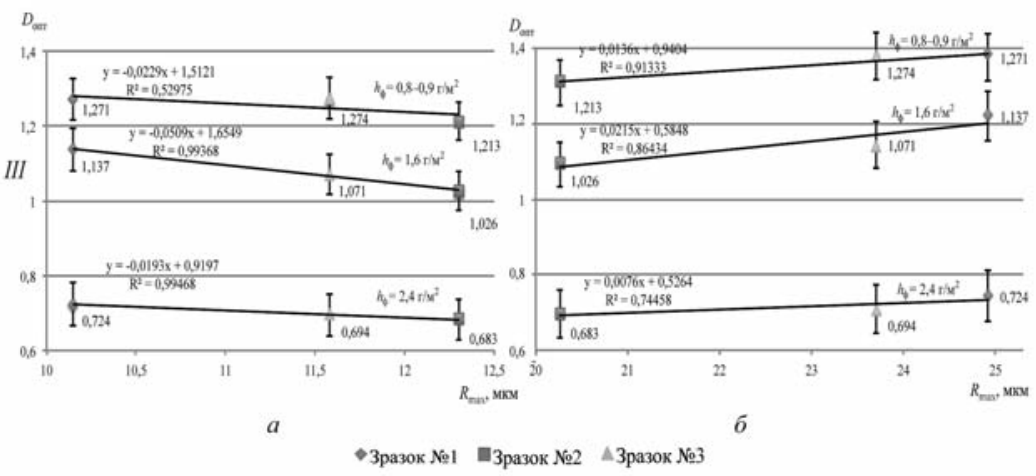

Рис. 2. Вплив параметрів шорсткості паперу $R_{a}, R_{z}, R_{\max }(I, I I, I I)$ на оптичну густину відбитків $\left(D_{\text {опт }}\right)$ : a - дані отримані механічним контактним методом; б - дані отримані оптичним безконтактним 
Фрактальна розмірність поверхні паперу: $D_{\phi p}=D_{п р}+1$.

Кореляція фрактальної розмірності з параметрами, які залежать від шорсткості поверхні, показує вплив на оптичну густину відбитків та їх взаємозалежність. Можна стверджувати, що значення фрактальної розмірності $€$ більш корисними для оцінки відбитків, ніж параметри шорсткості, що видно з рис. 3.

Метод дослідження банкнотного паперу на основі теорії фракталів дає змогу виявити розходження в поверхневій структурі як у зоні з водяними знаками, так і поза їх межами. Отже, було досліджено вплив фрактальної розмірності поверхні банкнотного паперу, що описано в статті [6] на оптичну густину відбитків.

Збільшення фрактальної розмірності поверхні паперу призводить до збільшення оптичної густини відбитків, що можна пояснити високим ступенем всотування фарби в структурно-пористу поверхню паперу (рис. 3) [6].

Під час дослідження впливу кількості фарби на оптичну густину, виявлено, що прийнята норма оптичної густини відбитків при друці чорною фарбою $\left(D_{\text {опт }}=1,25 \pm 0,05\right)$ досягається при кількості нанесеної фарби від 2,1 до 2,3 г/м².

Встановлено кореляції відбитків, що дозволяє прогнозувати отримання нормативних показників відбитків при використанні банкнотного паперу з відповідними властивостями, в тому числі для банкнотного паперу з непрозорістю - $\mathrm{H}=90-93,3 \%$, пористістю - П = 20-27 мл/хв., вбирною здатністю - В = 45,249,28 Кобб 60, показниками шорсткості $-\mathrm{R}_{\mathrm{a}}=1,41-1,66$ мкм, $\mathrm{R}_{\mathrm{Z}}=5,06-5,55$ мкм, $\mathrm{R}_{\max }=10,15$ 12,3 мкм, фрактальною розмір-
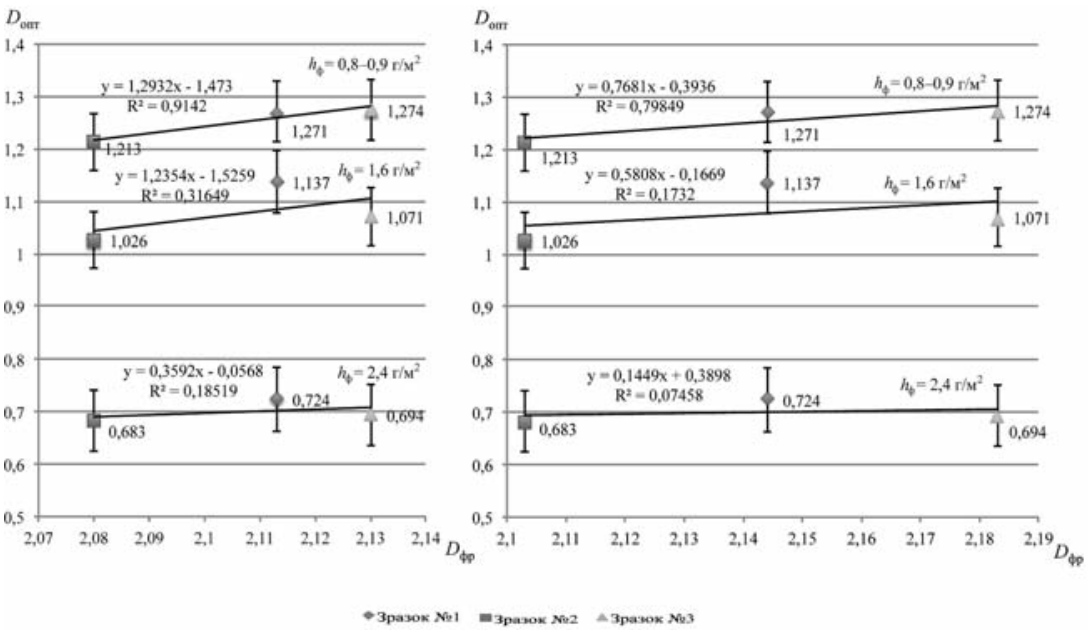

a

Рис. 3. Вплив фрактальної розмірності паперу $\left(D_{\phi p}\right)$ на оптичну густину відбитків $\left(D_{\text {опт }}\right)$, отриманих на банкнотному папері: a - дані отримані механічним контактним методом; б - дані отримані оптичним безконтактним методом 
ністю поверхні паперу $-\mathrm{D}_{\phi}=$ $=2,08-2,13$ за різної кількості фарби на відбитку.

Проаналізовані графічні залежності та апроксимації їх регресійними рівняннями, представлено в табл.

Таким чином, експериментально показано, що за нормовану величину оптичної густини відбитків можна приймати верхню межу з урахуванням допуску нормованої величини за стандартом ISO 126472 для банкнотного паперу. Експериментально підтверджено, що оптична густина відбитків залежить від непрозорості, пористості, вбирної здатності, показників шорсткості, фрактальної розмірності поверхні паперу [6] та кількості фарби на відбитку.

Також було здійснено кореляційний аналіз взаємного зв'яз- ку між структурними характеристиками захищеного паперу, зокрема в зоні водяного знака, та оптичними характеристиками відбитку та його звороту (рис. 4). Для проведення даного дослідження було використано три види паперу з водяними знаками: Security lune, Filidoro laid avorio, Chimere la hulpe, що задруковано тріадними фарбами 3 однаковою товщиною фарбового шару. Вимірювання проводились на ділянках з водяними знаками та без, на задрукованій стороні та на звороті відбитка. Вимірювання оптичної густини відбитка проводилось на денситометрі GretagMacbeth QUIKDence 200. Для отримання об'єктивного значення оптичної густини різних ділянок паперу, було враховано ширину водяного знаку та розмір вимірювальної апертури приладу.

Взаємозв'язок показників поверхні паперу та оптичної густини відбитків відповідно рівнянь регресії

\begin{tabular}{|c|c|c|c|}
\hline \multirow{2}{*}{$\begin{array}{c}\text { Показники } \\
\text { поверхні паперу }\end{array}$} & \multicolumn{3}{|c|}{ Рівняння регресії } \\
\hline & Зразок 1 & Зразок 2 & Зразок 3 \\
\hline $\mathrm{H}, \%$ & $\begin{array}{c}0,0118 D_{\text {опт }}- \\
-0,3806\end{array}$ & $\begin{array}{c}0,0302 \mathrm{D}_{\text {опт }}- \\
-1,6802\end{array}$ & $0,0112 D_{\text {опт }}+0,226$ \\
\hline П, мл/хв. & $\begin{array}{c}-0,0059 \mathrm{D}_{\text {опт }}+ \\
+0,8416\end{array}$ & $\begin{array}{c}-0,0153 D_{\text {опт }}+ \\
+1,4463\end{array}$ & $\begin{array}{c}-0,0066 \mathrm{D}_{\text {опт }}+ \\
+1,4105\end{array}$ \\
\hline В, Кобб 60 & $\begin{array}{c}0,0135 \mathrm{D}_{\text {опт }}+ \\
+0,6172\end{array}$ & $\begin{array}{c}0,0273 D_{\text {опт }}- \\
-0,2082\end{array}$ & $\begin{array}{c}0,0102 \mathrm{D}_{\text {опт }}+ \\
+0,2198\end{array}$ \\
\hline $\mathrm{R}_{\mathrm{a}}, \mathrm{MKM}$ & $\begin{array}{c}-0,0434 D_{\text {опт }}+ \\
+0,8364\end{array}$ & $\begin{array}{c}-0,1485 \mathrm{D}_{\text {опт }}+ \\
+1,5437\end{array}$ & $\begin{array}{c}-0,1541 \mathrm{D}_{\text {опт }}+ \\
+1,736\end{array}$ \\
\hline $\mathrm{R}_{\mathrm{z}}, \mathrm{MKM}$ & $\begin{array}{c}0,0273 \mathrm{D}_{\text {опт }}+ \\
+0,2134\end{array}$ & $\begin{array}{c}0,0215 D_{\text {опт }}+ \\
+0,5848\end{array}$ & $\begin{array}{c}-0,0045 D_{\text {опт }}+ \\
+1,3336\end{array}$ \\
\hline $\mathrm{R}_{\max }, \mathrm{MKM}$ & $\begin{array}{c}0,0076 \mathrm{D}_{\text {опт }}+ \\
+0,5264\end{array}$ & $\begin{array}{l}0,0215 D_{\text {Oחт }}+ \\
+0,5848\end{array}$ & $\begin{array}{l}0,0136 \mathrm{D}_{\text {опт }}+ \\
+0,9404\end{array}$ \\
\hline $\mathrm{D}_{\phi p}$ & $\begin{array}{c}0,1449 \mathrm{D}_{\text {опт }}+ \\
+0,3898\end{array}$ & $\begin{array}{c}0,5808 \mathrm{D}_{\text {опт }}- \\
-0,1669\end{array}$ & $\begin{array}{c}0,7681 \mathrm{D}_{\text {опт }}- \\
-0,3936\end{array}$ \\
\hline $\mathrm{h}_{\phi}, \Gamma / \mathrm{M}^{2}$ & $\begin{array}{c}0,3307 D_{\text {опт }}+ \\
+0,5198\end{array}$ & $\begin{array}{l}\text { 0,3862 Dопт + } \\
+ \text { 0,3209 }\end{array}$ & $\begin{array}{c}0,3784 \mathrm{D}_{\text {опт }}+ \\
+0,3723\end{array}$ \\
\hline
\end{tabular}


Виявлено, що зі збільшенням значень $\mathrm{R}_{\mathrm{a}}$ спостерігається зменшення оптичної густини відбитка та збільшення оптичної густини його звороту (тобто перебивання). Усереднене для чотирьох фарб значення кореляції склало 0,78 та 0,65 для відбитків та звороту відповідно. У разі підвищення оптичної густини паперу на просвіт спостерігається збільшення оптичної густини відбитка та зменшення оптичної густини звороту відбитка; кореляція 0,64 та 0,73 для відбитків та звороту відповідно. Спостері-
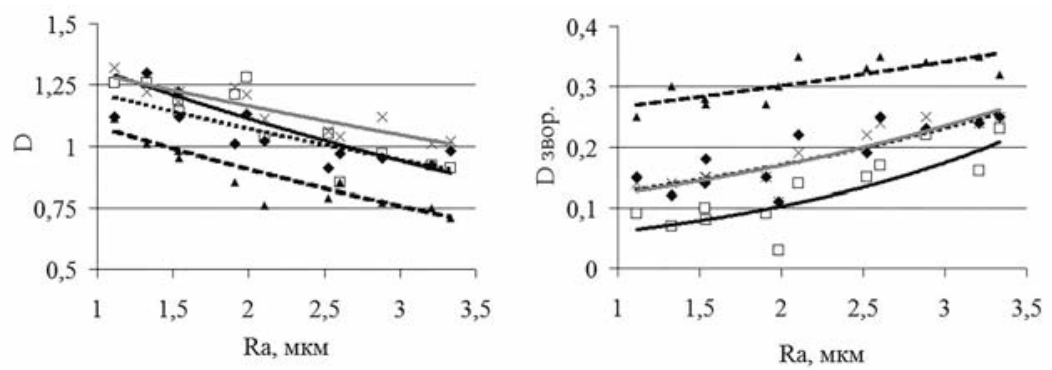

a
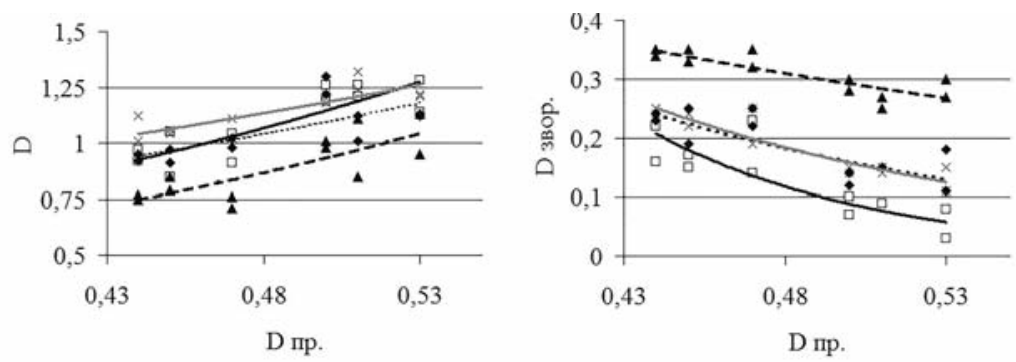

б
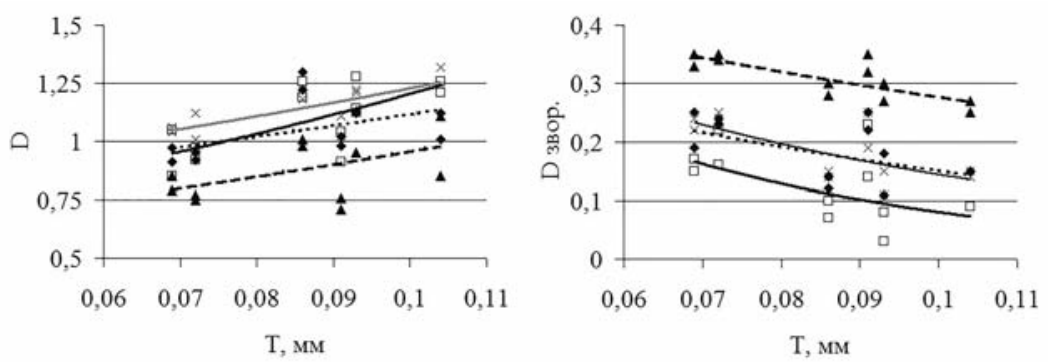

B

Рис. 4. Кореляція шорсткості (а), оптичної густини паперу, виміряної на просвіт (б), товщини паперу (в) та оптичної густини відбитків (ліворуч) та їх звороту (праворуч)

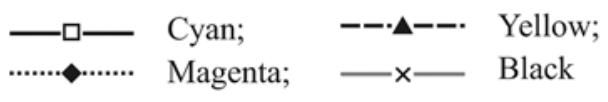


гається тенденція до збільшення оптичної густини відбитка та зменшення оптичної густини звороту відбитка зі збільшенням товщини паперу, хоча кореляція не є високою [9].

\section{Висновки}

На основі аналізу отриманих результатів та регресійних рівнянь знайдено взаємозв'язок характеристик поверхні банкнотного паперу, фарби, кількості фарби на відбитку, які корелюються з оптичними характеристиками, що дозволяє встановлювати контроль та управління якістю. Виявлено, що зі збільшенням значень $R_{a}$ спостерігається зменшення оптичної густини відбитка та збільшення оптичної густини його звороту (тобто перебивання). 3 підвищенням оп- тичної густини паперу на просвіт спостерігається збільшення оптичної густини відбитка та зменшення оптичної густини звороту відбитка. Спостерігається тенденція щодо збільшення оптичної густини відбитка та зменшення оптичної густини звороту відбитка зі збільшенням товщини паперу. Отримані експериментальні дані підтвердили теоретичні розрахунки. Похибка між експериментальними даними й теоретичними розрахунками становить 5-10\%. Перевага даної роботи полягає в тому, що в умовах багатосерійного виробництва банкнотної продукції дозволяє контролювати показники якості відбитків для більшого числа матеріалів, порівняно з регламентованими нормами стандартів.

\section{Список використаної літератури}

1. ISO 12647-2:2004. Полиграфические технологии. Управление процессами цветоделения, изготовления цветопроб и тиражных оттисков. Часть 2: Офсетная печать. - Введ. 15.11.04. - М. : Изд-во стандартов, 2004. -25 c.

2. Киричок П. О. Захист цінних паперів та документів суворого обліку / П. О. Киричок, Ю. М. Коростіль, А. В. Шевчук. - Київ : НТУУ «КПІ», 2008. — 368 с.

3. Кисельова О. Филигранная работа / О. Кисельова // Водяной знак. 2008. - № 1-2. - С. 39-41.

4. Луцків В. В. Апроксимація залежності оптичної щільності від товщини шару фарби на відбитку / М. Луцків, П. Малачківський // Квалілогія книги : зб. наук. пр. - Львів : УАД, 2005. - С. 95-102.

5. Величко О. Проблеми фарбоперенесення в плоскому офсетному друці / О. Величко, О. Зоренко, О. Розум // Друкарство. - 2002. — № 5. C. $75-77$.

6. Киричок Т. Ю. Моделювання структури поверхні банкнотного паперу на основі теорії фракталів / Т. Ю. Киричок, Т. Є. Клименко, О. В. Рибак // Наукові вісті НТУУ «КПІ». - 2016. - № 2. - С. 33-42.

7. Киричок Т. Ю. Мікрогеометрія поверхні паперу з водяними знаками / Т. Ю. Киричок, Т. Є. Клименко, Н. Л. Малкуш // Технологія і техніка друкарства : зб. наук. праць. - Київ, 2009. - № 4. - С. 130-137. - Режим доступу : http://ttdruk.vpi.kpi.ua/article/view/57869.

8. Климова Е. Д. Зависимость качества оттисков и стабильность процесса печатания от свойств печатной бумаги / Е. Д. Климова // Вестник : моск. гос. ун-т печати. - № 10. - М., 2005. - С. 63-66. 
9. Киричок Т. Ю. Моделювання зміни кольору звороту відбитків, отриманих на папері з водяними знаками, з урахуванням структурних характеристик паперу та параметрів фарби / Т. Ю. Киричок, Н. Л. Талімонова, О. В. Катрук // Вісник ждту. - 2015. - № 4(75). - С. 45-50.

\section{References}

1. (2004). ISO 12647-2:2004. Printing technologies. The management of the processes of color separation, production of proofs and run imprints. Part 2: Offset printing. Moscow: Izd-vo standartov [in Russian].

2. Kyrychok, P. O. \& Korostil, lu. M. \& Shevchuk, A. V. (2008). Zakhyst tsinnykh paperiv ta dokumentiv suvoroho obliku [Protection of securities and documents of strict accounting]. Kyiv : NTUU 'KPI' [in Ukrainian].

3. Kisel'ova, O. (2008). Filigrannaja rabota [Filigree]. Journal of Vodjanoj znak - Watermark, 1-2, 39-41 [in Russian].

4. Lutskiv, M. \& Malachkivskyi, P. (2005). Aproksymatsiia zalezhnosti optychnoi shchilnosti vid tovshchyny sharu farby na vidbytku [Approximation of the dependence of optical density on the thickness of the layer of ink on the imprint]. Journal of Kvalilohiia knyhy - Quadilogy of books, 95-102. Lviv: UAD [in Ukrainian].

5. Velychko, O. \& Zorenko, O. \& Rozum, O. (2002). Problemy farboperenesennia v ploskomu ofsetnomu drutsi [Problems of ink transfer in the flat offset printing]. Journal of Drukarstvo - Typography, 5, 75-77 [in Ukrainian].

6. Kyrychok, T. lu. \& Klymenko, T. le. \& Rybak, O. V. (2016). Modeliuvannia struktury poverkhni banknotnoho paperu na osnovi teorii fraktaliv [Modeling of the surface structure of the banknote paper on the basis of the theory of fractals]. Journal of Naukovi visti NTUU 'KPI' - Scientific news of NTUU 'KPI', 2, 33-42 [in Ukrainian].

7. Kyrychok, T. lu. \& Klymenko, T. le. \& Malkush, N. L. (2009). Mikroheometriia poverkhni paperu z vodianymy znakamy [Micro geometry of the surface of the paper with watermarks]. Journal of Tekhnolohiia i tekhnika drukarstva Technology and Technique of Typography, 4, 130-137. Retrieved from http://ttdruk.vpi.kpi.ua/article/view/57869 [in Ukrainian].

8. Klimova, E. D. (2005). Zavisimost' kachestva ottiskov i stabil'nost' processa pechatanija ot svojstv pechatnoj bumagi [The dependence of the quality of the imprints and the stability of the printing process on properties of printed paper]. Journal of Vestnik: mosk. gos. un-t pechati - Bulletin: Moscow State University of Printing, 10, 63-66 [in Russian].

9. Kyrychok, T. lu. \& Talimonova, N. L. \& Katruk, O. V. (2015). Modeliuvannia zminy koloru zvorotu vidbytkiv, otrymanykh na paperi z vodianymy znakamy, z urakhuvanniam strukturnykh kharakterystyk paperu ta parametriv farby [Modeling change the color of turnover of the imprints produced on paper with a watermark, taking into account the structural characteristics of the paper and ink options]. Journal of Visnyk ZhDTU - Bulletin of ZhSTU, 4(75), 45-50 [in Ukrainian]. 
Проведен корреляционный анализ взаимосвязи между характеристиками защищенной от подделки бумаги и оптическими характеристиками оттисков.

Ключевые слова: корреляционный анализ; банкнотная бумага; водяной знак; шероховатость бумаги; оптическая плотность.

The correlation analysis of intercommunication of properties of surface banknote paper and optical characteristics of prints.

Keywords: correlation analysis; banknote paper; watermark; the roughness of paper; optical density.

Рецензент - О. І. Лотоцька, к.т.н., доцент, КПІ ім. Ігоря Сікорського

Надійшла до редакції 28.12.16 